\title{
A FORMAÇÃO DOCENTE NA VISÃO DOS MINISTROS DE EDUCAÇÃO E CHEFES DE ESTADO DA UE*
}

\author{
Maria Abádia da Silva \\ da Universidade de Brasília (UnB).
}

\begin{abstract}
RESUMO: O presente artigo problematiza o ordenamento político que deu origem ao Espaço Europeu de Educação Superior e, nele, a formação docente instituída à luz dos Comunicados da Comissão Europeia, documentos aprovados e resoluções publicadas no Diário Oficial da União Europeia. Esses desencadeiam um modelo de educação e formação de profissionais para os Estados- membros, voltado para a aprendizagem ao longo da vida, propondo converter a universidade e a escola em agências de serviços. O texto analisa, no ciclo de conferências de ministros e chefes de Estado, os eixos estratégicos, as competências básicas, habilidades e aptidões que se exigem dos alunos, de modo a aproximar a escola das empresas, além de estimular o espírito empresarial nos indivíduos em todos os níveis. Aponta, ainda, que se associa a formação de professores a um tipo de crescimento econômico conservador em que flexibilidade, empregabilidade, competitividade, individualismo, eficiência, cultura digital e racionalidade são pressupostos condutores das políticas e práticas de educação.
\end{abstract}

PALAVRAS-ChAVE: Formação docente. Educação e formação no EEES. Política educacional.

INTRODUÇÃO

Durante décadas, o Banco Mundial interferiu na elaboração de políticas, em que reduzia o lugar do professor, para a educação básica pública dos países. Em suas proposições, incentivou que - com os insumos, livro didático, recursos e equipamentos tecnológicos e laboratoriais - se

\footnotetext{
* Artigo recebido em 10/09/2012 e aprovado em 05/12/2012.
} 
alcançariam os resultados e metas desejados, sem enxergar o trabalho formativo, político e pedagógico dos docentes. Em algumas ocasiões, enfatizou a formação a distância, rápida e com diminuição de tempo, além de reduzir a educação ao domínio de conhecimentos em matemática, português e ciências. Seus diretores e técnicos insistiam na elevação do número de estudante por turmas e salários baixos, associando exames, resultados e desempenho como premiação monetária aos professores. Por diversas vezes, os diretores, consultores e burocratas imputaram aos docentes o fracasso dos estudantes nos exames e testes internacionais. Também são constantes as tentativas de avaliação nacional dos docentes, sem proceder a melhorias nas condições de trabalho, jornada, carreira e salários. No entanto, para esses burocratas, pouco importa a formação inicial dos docentes; suas críticas aos governos nacionais são por dispensarem à educação pública uma parcela significativa do orçamento do Estado, sem que se obtenham resultados efetivos, quantificáveis e consoantes com as demandas do mercado.

Destarte, esses homens de negócios movem-se nas redes de poder e de decisões políticas internacionais e ambicionam a abertura da educação para o mercado livre. A presença deles nos circuitos políticos reforça a crença de que sejam adotadas ações de flexibilidade, produtividade, eficácia, espírito empresarial, racionalidade e descentralização e, assim, criar-se-iam as condições para se aproximar a universidade e a escola das empresas, gerando consumidores e competidores para disputas no mercado. E nesse alinhamento das relações políticas, se sobressai a primazia dos interesses econômicos, ao tempo em que esses senhores pressionam os governos locais a: a) manter os salários dos docentes reduzidos; b) diversificar as instituições de educação superior; c) executar parcerias público-privadas; d) implementar um sistema nacional de avaliação básica e superior; e) e expandir a utilização da tecnologia nos cursos a distância. Esse desatino foi, em parte, freado pela mobilização do Movimento Docente, sindicatos e associações científicas. Mesmo assim, o projeto neoliberal foi levado a cabo pelos governos nacionais, ao assumirem as condicionalidades externas, modificando parte das estruturas das instituições educacionais e, ao mesmo tempo, produzindo outras culturas e valores, e renovando-os sob a lógica competitiva e individualista (TATO, 2005; GENTILI, 1998; FONSECA, 1995).

Entretanto, a partir da década de 1990, aceleraram-se as modificações nas relações sociais, familiares, educacionais, nas formas de trabalho e nas profissões; em parte, decorrentes das tecnologias da informação e da comunicação (TIC) e, de outra, porque a formação inicial, adquirida nas instituições formadoras, tornou-se distante e em descompasso com as exigências atuais 
que pressionam os processos de reestruturação. Esse movimento cíclico trouxe implicações e outro ordenamento nas relações sociais, no trabalho, na universidade e na escola, criando expectativas sobre a formação docente.

Se antes, diretores, burocratas e experts do Banco Mundial não admitiam o valor e nem reconheciam o trabalho social, político e pedagógico dos professores, por que, agora, a União Europeia toma o trabalho pedagógico e o transforma em objeto para se traçar estratégias e indicadores econômicos? O que mudou? Por que essas instituições multilaterais passaram a direcionar a política de formação docente nos países?

Partindo-se desse movimento global e local, desse entrelaçamento entre os processos econômicos e sociais, o texto a seguir, na primeira parte, problematiza a política de formação docente, inscrita no Espaço Europeu de Educação Superior (EEES) e publicada no Diário Oficial da União Europeia (DOCE), nos Comunicados da Comissão Europeia (COM), ${ }^{1}$ e nos documentos aprovados nas três instâncias de discussão, decisão e execução da União Europeia: Comissão Europeia, Conselho Europeu e Parlamento Europeu, com sede em Bruxelas. $E$, na segunda parte, aponta algumas aproximações entre o EEES e a OCDE, com o intento de evidenciar o modelo de formação docente subjacente no universo das políticas públicas.

Passemos, então, à reflexão.

\section{O QUE PROPÕE OS DOCUMENTOS DO EEES SOBRE FORMAÇÃO SUPERIOR?}

Durante a década de 1990, burocratas, executivos e planejadores políticos das agências e instituições de créditos identificaram o desemprego, a formação universitária distante do mercado, a circulação irregular do comércio e as novas exigências do setor de serviços como fatores limitadores do crescimento da indústria; esses explicavam os resultados negativos referentes às metas e objetivos econômicos propostos. Nessa situação, sinalizaram que, entre esses fatores inibidores, estava a qualidade da educação, a formação docente e a falta de conexão entre a escola e a empresa; daí a urgência de se impulsionarem políticas de correção desse desvio para realinhar os ganhos empresariais.

Foi nesse contexto - de incompatibilidades entre a formação superior ofertada nas universidades e as necessidades e dilemas econômicos e sociais - que se criou o Espaço Europeu de Educação Superior (EEES). Esse processo ocorreu a partir da Declaração de Sorbonne (1998) e a Declaração de Bolonha (1999) e foi assinado por governos de vinte e nove Estados-membros da União Europeia. Como objetivos para se reestruturar as instituições universitárias na Europa, propuseram então: uma compatibilização da estrutura acadêmica 
em dois níveis, graduação e pós-graduação (mestrado e doutorado); a adoção do sistema de créditos e de reconhecimento de diplomas e títulos; a mobilidade de estudantes, docentes e investigadores; a cooperação e integração institucionais para os programas e planos de estudos.

O EEES é uma forma de articulação política capitaneada pelos chefes de Estado e ministros de Educação, com a finalidade de recompor e reconfigurar o modelo de educação superior, em especial as universidades, recolocando princípios e funções em consonância com as exigências do crescimento econômico da Europa. Busca a convergência de diferentes sistemas de educação, a comparabilidade de títulos e a integração de planos de estudos, harmonia de diplomas e a mobilidade para estudantes, professores e pesquisadores. Nesses termos, propõe um outro ordenamento para a universidade, situando-a como renovadora e inovadora, atribuindo-lhe capacidade para transcender a comunidade europeia e se projetar para os setores econômicos, cultural e formativo (SUÁREZ, 2010).

Assim, além de ser uma estratégia política dos governos europeus, o EEES enseja a ideia de um espaço geográfico (também o é), mas constitui uma maneira de organização política dos chefes de Estado e ministros de Educação que associam a pesquisa científica e tecnológica aos desígnios do mercado, por meio de leis, patentes, cifras, valores quantificáveis. E desse modo, nos tratados e acordos econômicos firmados, admitem-se, no seu interior, cláusulas e regras especificas para a educação superior, redefinindo funções e papéis consoantes com as exigências do mercado e da economia. Foi então, a partir da Declaração de Bolonha (1999), que os chefes de Estado e ministros dos países membros da União Europeia decidiram executar um processo de convergência para integrar, padronizar e unificar os procedimentos relativos a trocas e trâmites entre as universidades europeias. $O$ objetivo era facilitar a visibilidade, a circulação de estudantes e docentes, a equiparação dos diplomas e programas formativos, além de buscar superar a docência centrada no ensino para a docência centrada na aprendizagem, com foco no aprender a aprender, atraindo, assim, alunos não europeus para o crescimento econômico (SUÁREZ, 2010; RUÉ, 2007; EGUIZÁBAL, 2008).

Para esses senhores de negócios, a universidade permanecia, ainda, amarrada em burocracias, não cumprindo um papel essencial no crescimento econômico, pois a formação profissional dispensada aos estudantes não atendia às necessidades prementes das indústrias e dos serviços. Eles apontavam que a falta de domínio de competências, regras muito distintas e as limitações na formação inibiam o crescimento dos negócios entre os países, empresas transnacionais e redes de comunicação. 
Com esse raciocínio, entre 1995 e 2010, sucederam vários encontros em que os chefes de Estado e Ministros de Educação apontaram as deficiências na formação superior e determinaram um conjunto de ações, entre elas, uma política de formação docente a ser adotada na universidade. Observe que os documentos COM 5 final - Ensinar e aprender: rumo à sociedade cognitiva (1995) e Crecimiento, competitividad y empleo (1993) - foram elaborados no calor de uma profusão ideológica, quando também estava sendo divulgado, no circuito, o Relatório de Jacques Delores (1993), com ênfase no aprender a aprender, aprender a ser, aprender a fazer e aprender a viver juntos. O diagnóstico europeu, no documento Ensinar e aprender: rumo à sociedade cognitiva, apontava para"a necessidade de investir em capital humano, superar as limitações quanto ao uso das tecnologias, desenvolver uma política de empregos e lutar por uma Europa do conhecimento, competitiva, dinâmica e eficaz" (TATO, 2005, p. 253). E, assim, sublinhava ser vital o papel da educação e da formação para a promoção da competitividade europeia (ANTUNES, 2005).

Esses formuladores de políticas da União Europeia definiram os seguintes objetivos para a formação superior: fomentar a aquisição de novos conhecimentos; aproximar a escola e a universidade da empresa; lutar contra a exclusão social; dominar três línguas europeias; buscar igualdade no investimento físico e no investimento em formação. Durante os encontros, os ministros atribuíram, no papel dado à universidade, a formação docente deslocada do ensino para a aprendizagem, de modo que a aposta foi feita no indivíduo. Conferiram a ele toda responsabilidade para aprender e seguir aprendendo, ter aptidão e adquirir capacidades, competências e as habilidades necessárias para disputar emprego, ou saber como adquiri-las.

No mundo moderno, o conhecimento em sentido lato pode ser definido como uma acumulação de saberes fundamentais, de competências técnicas e de aptidões sociais. É pela combinação equilibrada desses saberes - adquiridos no sistema de ensino formal, na família, na empresa, por diversas redes de informação - que se cria o conhecimento geral transmissível, mais favorável ao emprego. Os conhecimentos de base constituem o alicerce da aptidão individual para o emprego. Trata-se do domínio do sistema educativo e de formação formal por excelência. Na educação de base, convém encontrar um justo equilíbrio entre a aquisição dos saberes e as competências metodológicas que permitem aprender por si mesmo, competências essas que, hoje, se faz necessário desenvolver (COM 59, 1995, p. 17).

Nesse documento, também, foram apontados alguns desafios, da década de 1990, de como fazer da educação e da formação eixos para o progresso e crescimento europeu. Desse modo, os formuladores fixaram uma 
crença no mercado e insistiam na aptidão individual, assim como na busca e utilização de conhecimentos, nas competências básicas e cognitivas, no saber comunicar-se, saber relacionar-se em redes, saber cooperar e aprender. Para progredir em termos econômicos, perseveravam os chefes de Estado que a mobilidade do diploma era fundamental, junto com outras formas de intercâmbio e de cooperação das empresas com maiores investimentos, adoção de flexibilidade, inovação, qualidade, formação contínua, qualificação profissional, aprendizagem individual, além de saber reconhecer as competências básicas dos novos tempos (COM 59, 1995, p. 38-39).

A Europa deve investir na educação para elevar o nível geral de formação e de qualificação dos trabalhadores e do conjunto da população ativa, pelo ensino inicial e pelo incentivo à aquisição de novos conhecimentos durante toda a vida. Esse investimento imaterial deve também permitir fazer face às grandes tendências da evolução do mercado empregatício: inadequação entre as qualificações solicitadas e as qualificações disponíveis, questões demográficas, desenvolvimento das atividades dos serviços, da organização e do conteúdo do trabalho (p. 32).

A crença dos ministros, burocratas e empresários em geral era de que suas decisões políticas, associadas às TIC, produziriam resultados na formação realizada na universidade e escola, subordinando-as aos ritos de mercado. Essa crença cega permitiu que - no documento COM 678 final, Tornar o espaço europeu de aprendizagem ao longo da vida uma realidade (2001) esses homens de negócios fossem mais contundentes, pois reconheciam que a Europa ainda apresentava um ritmo inadequado de crescimento. E para tornar o espaço europeu de aprendizagem ao longo da vida uma realidade, fez-se necessária uma gradual integração entre educação e formação (p. 7). As exigências advindas das TIC, os ciclos de crises, as limitações dos diplomas, os efeitos da globalização econômica e da circulação das pessoas em busca de melhores condições de vida reforçaram a crença dos governos e ministros de Estado em um tempo novo, denominado sociedade do conhecimento. Desse modo, afirmavam que

a aprendizagem ao longo da vida não pode ficar reduzida a uma visão puramente econômica ou à educação dos adultos; deveria cobrir integralmente o espectro da aprendizagem formal, não formal e informal, e os objetivos da aprendizagem, incluindo a cidadania ativa, o desenvolvimento individual e a inclusão social, bem como os aspectos relacionados com o emprego. Os princípios que regulam a aprendizagem ao longo da vida e orientam a sua execução eficaz colocam o papel central do aprendente, na importância da igualdade de oportunidades e na qualidade e pertinência das oportunidades de aprendizagem. (COM 678, 2001, p. 4) 
Nos intentos propostos por meio de planos e programas, os ministros, governos e executivos puseram centralidade no indivíduo e reforçaram os elementos de aptidão e os indicadores de empregabilidade e adaptabilidade (p.10). Assim definiram o conceito de aprendizagem ao longo da vida, como sendo "toda a atividade de aprendizagem em qualquer momento da vida, com o objetivo de melhorar os conhecimentos, as aptidões e competências, no quadro de uma perspectiva pessoal, cívica, social elou relacionada com o emprego" (COM 678, 2001, p.10). Na visão desses governos, a sociedade do conhecimento trouxe outras necessidades para os profissionais liberais e para o livre mercado. Urgia uma formação para a empregabilidade ordenada aos níveis globais de investimento público e privado, e esses deveriam basearse em uma partilha de responsabilidades entre os governos, as autoridades públicas, os empregadores, os parceiros sociais e os cidadãos (p.14).

Nesse entremeio, prosseguem os chefes de Estado, ministros e empresários com o intuito de alcançar outro patamar econômico e, para tanto, puseram em marcha a valorização da aprendizagem, ao fomentar uma cultura da aprendizagem, promover o acesso a ela, adotar mecanismos de procura da excelência na universidade. A estratégia era fomentar e facilitar vários tipos e processos de aprendizagem; e prescreveram como metas: aproximar os aprendentes das oportunidades de emprego, unificar escola e empresa e, ainda, "determinar o conteúdo do pacote de competências básicas e digitais" (COM 678, 2001, p. 28). E, para finalizar, enfatizavam também a necessidade de "transição do conhecimento para a competência e do ensino para a aprendizagem, conferindo ao aprendente o papel do protagonista". [...] Essa transição implica que, "desde a mais tenra idade, os indivíduos devem aprender a aprender e assumir a responsabilidade da sua própria aprendizagem, procurar ativamente adquirir conhecimentos e desenvolver as suas competências" (p. 29).

Apartados das circunstâncias socioculturais, dos processos migratórios, das precárias condições de vida de ampla parcela da população, esses senhores apostam nas boas intenções, programas, planos e metas fixadas para fazer as reformas. Tal confiança pode ser identificada no modus operandi de conduzir as decisões políticas, entre elas, a publicação no Diário Oficial do Estado (DOE), no Diário Oficial das Comunidades Europeias (DOCE) e no Boletim Oficial. São ações que pressionam os gestores das instituições educacionais a adotar uma outra cultura política sob o mote: aprendizagem ao longo da vida. Observe a Resolução do Conselho Europeu sobre as propostas e encaminhamentos. 
Resolução do Conselho de 27 de Junho de 2002 sobre a aprendizagem ao longo da vida. (2002/C 163/01)

\section{O CONSELHO DA UNIÃO EUROPEIA,}

Considerando o seguinte:

(1) A educação e a formação constituem um meio indispensável para promover a coesão social, a cidadania ativa, a realização pessoal e profissional, bem como a adaptabilidade e a empregabilidade. A aprendizagem ao longo da vida facilita a livre mobilidade dos cidadãos europeus e permite que se alcancem os objetivos e aspirações dos países da União Europeia (a saber, uma maior prosperidade, competitividade, tolerância e democracia). A aprendizagem ao longo da vida deve assegurar que qualquer pessoa possa obter os conhecimentos necessários para tomar parte, como cidadão ativo, na sociedade do conhecimento e no mercado de trabalho.

SALIENTA que a aprendizagem ao longo da vida deve incluir a aprendizagem desde a idade pré-escolar até depois da aposentação, incluindo todo o espectro da aprendizagem formal, não formal e informal. Além disso, a aprendizagem ao longo da vida deve ser entendida como uma atividade de aprendizagem global que decorre durante toda a vida, com o objetivo de melhorar conhecimentos, proficiências e competências numa perspectiva pessoal, cívica, social e/ou associada ao emprego. Finalmente, os princípios a considerar neste contexto devem ser: o indivíduo como sujeito da aprendizagem, o destaque para a importância de uma real igualdade de oportunidades e a qualidade na aprendizagem.

RECONHECE que deve ser dada prioridade:

- à oferta de oportunidades para adquirir e/ou atualizar competências essenciais, incluindo novas competências essenciais como as tecnologias da informação, as línguas estrangeiras, a cultura tecnológica, o espírito empresarial e as competências sociais;

- à formação, recrutamento e atualização dos professores e formadores para o desenvolvimento da aprendizagem ao longo da vida.

Mais adiante convoca os Estados-membros a:

Melhorarem o ensino e a formação dos professores e formadores implicados na aprendizagem ao longo da vida a fim de que estes adquiram as aptidões para o ensino necessárias na sociedade do conhecimento, promovendo assim, entre outros objetivos, o acesso a aprendizagem das línguas europeias, o acesso de todos às TIC e uma maior participação em estudos científicos e técnicos. 
A empreitada para se alcançarem as metas veio com o documento COM 779 final - Investir eficazmente em educação e em formação: um imperativo europeu (2003) - quando se passou a utilizar o termo sistemas de educação e de formação de maneira imperativa. A aposta feita era no indivíduo em abstrato e universal, portador de competências cognitivas e digitais. $\mathrm{O}$ propósito era aproximar a universidade e a escola das empresas e, ao abordar as prioridades dos recursos financeiros e percentuais, "assegurar que a Europa seja reconhecida, à escala mundial, como uma referência pela qualidade e relevância dos seus sistemas e instituições de educação e de formação [...] e assegurar que ela seja o destino preferido dos estudantes, acadêmicos e investigadores de outras regiões do mundo" (COM 779, 2003, p. 5). A primazia dos elementos econômicos foi evidenciada quando

o Conselho de (Educação) e a Comissão sublinharam que a União Europeia só se conseguiria tornar uma economia baseada no conhecimento, mais dinâmica e competitiva do mundo, se a educação e a formação funcionassem como fatores de crescimento econômico, de investigação e inovação, de competitividade, de emprego sustentável e de inclusão social e de cidadania ativa. (COM 779, 2003, p. 5)

\section{Afirmaram que a educação e a formação deveriam}

servir de motor à nova economia e sociedade europeia baseada no conhecimento; ultrapassar os atrasos e as deficiências acumuladas ao longo do tempo em relação aos principais concorrentes; gerir uma evolução demográfica desfavorável; e superar acentuados desequilíbrios regionais que se verão agravados pelo alargamento durante o período crucial da transição. (COM 779, 2003, p. 11)

Ainda, nesse documento, afiançados pelos chefes de Estado e ministros de Educação, foram inscritos os eixos nucleares da política para a educação superior; alguns deles: competências básicas, cultura digital, capacidade para aprender a aprender, competências sociais e cognitivas, espírito empresarial e aprendizagem de três línguas estrangeiras, como instrumento dos indivíduos para disputarem os empregos (COM 779, 2003, p.18). Seguindo a mesma linha política, o documento COM 962 final Competências chaves para aprendizagem permanente (2006) - apresenta, de forma objetiva, oito competências essenciais para a aprendizagem permanente, realização pessoal, integração social, cidadania e emprego. São elas: comunicação em língua materna, comunicação em língua estrangeira, competência em matemática e ciências, competência tecnológica e digital, aprender a aprender, competências sociais e cívicas, possuir iniciativa e 
espírito empreendedor, e ter consciência das expressões culturais (COM 962, 2006). Em termos políticos, compuseram uma estratégia para reordenar e converter a universidade e a escola em agências prestadoras de serviços, a ponto de - na COM 392 final, Melhorar a qualidade da formação do professorado (2007) - afirmarem, tal como a OCDE, existir uma relação entre os resultados dos estudantes e a qualidade de ensino, e que a aprendizagem está relacionada com a formação docente.

[...] los profesores deben desempeñar un papel fundamental a la hora de preparar a los alumnos a ocupar el lugar que les corresponde en la sociedad y en el mundo del trabajo. En todos los momentos de su carrera, los profesores deben poseer o ser capaces de adquirir toda la gama de conocimientos de las materias que imparten, así como las actitudes y capacidades pedagógicas que puedan ayudar a losjóvenes a alcanzar todo su potencial. (COM 392, 2007, p. 13)

Assim, para reordenar a educação e a formação dos professores, o Conselho Europeu instituiu e publicou por meio do Diário Oficial das Comunidades Europeias (DOCE), n. C142/1, de 14 de junho de 2002, os seguintes objetivos:

\section{Aumentar a qualidade dos sistemas de Educação e de formação}

- Melhorar a educação e a formação dos professores e formadores.

- Identificar as competências de que os professores e os formadores devem dispor, tendo em conta a evolução do seu papel na sociedade do conhecimento.

- Criar as condições que proporcionem aos professores e formadores o apoio adequado para poderem responder aos desafios da sociedade do conhecimento, na perspectiva da aprendizagem ao longo da vida.

- Assegurar um nível de acesso suficiente à profissão docente, em todas as disciplinas e a todos os níveis, e garantir a satisfação das necessidades a longo prazo da profissão, tornando ainda mais atrativos o ensino e a formação.

- Atrair para a docência e para a formação novos candidatos com experiência profissional noutros domínios.

- Motivar mais jovens a optar por estudos e carreiras no domínio da matemática, das ciências e da tecnologia.

\section{Facilitar o acesso de todos à educação e à formação}

- Assegurar que todos possam ter acesso à educação e à formação.

- Promover programas de aprendizagem flexíveis para todos.

- Promover a criação de redes de instituições de educação e de formação a diversos níveis, no contexto da aprendizagem ao longo da vida. 
3. Abrir os sistemas de educação e formação ao mundo exterior

- Promover o espírito de iniciativa e a criatividade em todo o sistema de educação e formação.

- Formar e desenvolver o espírito empresarial.

Fonte: Diário Oficial das Comunidades Européias - DOCE. No.C142/1.2002.

Os trechos anteriores indicam (e quase determinam) o lugar do professor e do estudante. Nessa direção política, ensejam modificar as relações entre formação superior e postos de trabalho disponíveis na Europa. Note que determinações de cariz econômica, conduzidas pela União Europeia, sinalizam que cabe ao individuo toda a responsabilidade para superar as fragilidades e dificuldades de se obter trabalho.

Dessa forma, ministros e governos advogam, como política de formação, o docente ser capaz de: superar a docência centrada no ensino para uma docência centrada na aprendizagem; indicar ao aluno como se aprende e onde ele pode buscar o conhecimento; conhecer e saber utilizar todas as tecnologias e metodologias didáticas; conduzir processos virtuais e presenciais; conhecer e aplicar modelos de avaliação mensuráveis e redirecionar objetivos; criar situações concretas de aprendizagens; possuir linguagens interculturais e ser um facilitador da aprendizagem.

Nesse sentido, nota-se ainda que as determinações políticas, econômicas e jurídicas, capitaneadas pela União Europeia, ensejam mudanças: a) na universidade, b) na formação superior, e c) nos cursos de graduação e pós-graduação. Importa, ainda, destacar o sentido econômico e mercantil atribuído à aprendizagem ao longo da vida, à destituição da dimensão política dos termos qualidade, eficiência da educação e formação, e à adoção do espírito empresarial e competitivo nas relações entre escola/ universidade e as empresas. A responsabilização do indivíduo pela sua formação e empregabilidade, a crença no currículo por competências básicas, digitais e cognitivas, a flexibilidade e adaptabilidade como meios para aproximar a escola e a universidade das empresas tornaram-se formas produtivas e compartilhadas no EEES.

\section{A FORMAÇÃO DOCENTE PARA A OCDE}

Criada em setembro de 1961, com sede em Paris, a Organização para a Cooperação e Desenvolvimento Econômico $(\mathrm{OCDE})^{2}$ conta com trinta países e tem entre os seus objetivos coordenar políticas econômicas e de estabilidade financeira. Nos últimos anos, tem se ocupado também de políticas sociais, 
em especial do cruzamento de indicadores, estratégias e metas educacionais com o nível de crescimento dos países.

Entretanto, desde 2002, a OCDE passou a coordenar o Programa Internacional de Avaliação de Estudantes (PISA) que reúne, em larga escala, especialistas com experiência em avaliação, priorizando a leitura, matemática e ciências, com a finalidade de criar um banco de dados e estatísticas educacionais dos países, além de produzir e divulgar indicadores padronizados, hierarquizados e com cruzamentos internacionais. Para tanto, coordena a aplicação de exames ou testes internacionais, com vista a monitorar como os alunos se encontram no final da escolaridade obrigatória e se adquiriram os conhecimentos, destrezas, competências e habilidades necessárias (BRIÑAS, 2010).

Por outro lado, desde 1997, por meio do projeto DeSeCo/OCDE, ${ }^{3}$ foram estabelecidas as competências nucleares a serem observadas pelos Estados-membros:

1. Usar as ferramentas tecnológicas de forma interativa: saber usar as linguagens, símbolos e textos de forma interativa, ter ou adquirir capacidade para usar o conhecimento, a tecnologia e a informação de forma interativa.

2. Saber interagir em grupos heterogêneos: relacionar-se bem com os outros, para cooperar, aprender a trabalhar em equipe e a resolver os conflitos.

3. Saber atuar de forma autônoma: adquirir destrezas para atuar dentro de grandes esquemas, conduzir planos de vida, projetos pessoais e coletivos, saber afirmar direitos e superar limites. (BRIÑAS, 2010)

Desde 2005, os especialistas da OCDE manifestaram interesse na formação dos docentes e no documento Attracting, developing, and retaining effective teacher (2005), e apresentaram estudos realizados em países, divulgando dados estatísticos sobre os professores. Esses experts indicam aos governos dos Estados-membros como melhorar a qualidade da educação para todos. Direcionam índices e metas a serem alcançadas, enfatizando que há uma relação entre o desempenho dos estudantes e a formação dos professores. Tecem duras criticas aos poderes públicos por dispensarem muitos recursos aos docentes, mas afirmam que não se recruta bons professores; é preciso formá-los ao longo de sua vida profissional, mantêlos vinculados ao sistema educativo e submetê-los a processos avaliativos constantes.

A OCDE, no documento Attracting, developing, and retaining effective teacher (2005), analisa a situação dos docentes e como atrair, formar e mantêlos nas escolas. Afirma que a aprendizagem e o desempenho dos alunos estão 
relacionados com a formação docente. Aponta, ainda, que o desprestígio social, a falta de confiança e de perspectivas profissionais, as condições de atuação em classe, as medidas de desprofissionalização, os baixos salários, o descaso das autoridades com a formação continuada, a ausência de tempo para preparo das tarefas e atividades, os raros programas de integração dos docentes novos, as aposentadorias, a escassez de docentes na Bélgica, Países Baixos e Suécia, a feminização, a faixa etária avançada e a diminuição do número de alunos na escola secundária são situações que requerem medidas dos governos.

Em outro documento, intitulado Creating, effective teaching and learning environments: firts results form Talis (2009), distinguem-se dois modelos de contratação de docentes. No sistema de carreira, o docente, geralmente em idade jovem, é contratado por serviço público, pelas credenciais acadêmicas ou exame, e sua promoção na carreira ocorre por antiguidade. Esse sistema, em função da expansão escolar, consome muitos recursos dos governos. $O$ outro é o sistema de contrato descentralizado, feito sob demanda pelas escolas ou pelas comunidades no âmbito local ou regional. Nesse, se o desempenho for baixo, o docente pode ser demitido e, então, tem-se o risco de alta rotatividade. Para atrair e manter os professores nas escolas, sugere-se avaliar e premiar os mais produtivos e de excelência, propondo gratificações e salários diferenciados (MAUÉS, 2011). A OCDE reafirma que é necessário colocar ênfase na eficácia, na performance e controle sobre os resultados obtidos, exigindo-se, ainda, prestação de contas sistemática. Defende a formação a distancia e a criação de programas permanentes de capacitação, programas esses voltados para aquisição de habilidades interpessoais, relacionais e comunicacionais, inclusive com avaliações constantes. Acentua o desperdício do Estado com pagamento de professores cujos resultados de desempenho dos estudantes são irrisórios. Esses elementos os fazem acreditar que a questão está no professor, no indivíduo e, portanto, insistem em sistemas rígidos de avaliação dos docentes.

Em sintonia com o OCDE, os documentos da Agência de Informação sobre a Educação na Europa (EURYDICE, 2004 e 2005) - em especial La profesión docente en Europa: perfil, tendencias e intereses - apresentam as metas para melhorar a formação docente e a qualidade do ensino: a) tornar a profissão atraente para os jovens; b) buscar certa uniformidade nos modelos de formação profissional; c) exigir habilidades e competências para trabalhar com tecnologias; d) saber conduzir a gestão; e) saber administrar e saber trabalhar com grupos multiculturais e pessoas com necessidades especiais; f) saber conviver com as diversidades etnicoculturais; g) possuir domínio de 
comunicação intercultural; h) e possuir habilidades financeiras e organizativas para resolução de problemas. Esses são os requisitos a serem alcançados pelos governos na educação.

Nessa direção, os governos dos Estados-membros vinculados à OCDE subscrevem os indicadores internacionais como se fossem nacionais, além de vincular os recursos ao desempenho dos alunos. Com efeito, aproximar a escola e a universidade das empresas, utilizar os recursos financeiros de forma compartilhada com outros parceiros, adotar sistemas de avaliação docente e ênfase nas competências sob a ótica neoliberal são eixos centrais na política educacional que circula entre os países da União Europeia.

\section{AproximaçÕES ENTRE OS MODELOS DE FORMAÇÃO DOCENTE: EEES E OCDE}

Pode-se argumentar que "lo global, para adquirir realidad, tiene que ser traducido o transladado al nível de lo local" (RUÉ, 2007, p. 34) e que, nas instituições educacionais, existem dois tipos de cultura: a adaptação às mudanças; e tomar as mudanças como um processo político, considerando que as políticas não são estendidas de forma linear e neutra para os Estados e universidades. Essas instituições possuem uma cultura organizacional e autonomia para avaliar, eleger, decidir seus rumos e mediar o jogo de forças políticas, econômicas e sociais partícipes do processo. Os estudos de Vinão (2002, p. 90.) apontam que "a posição e os diferentes pontos de vista dos reformadores e dos professores determinam o relativo fracasso das reformas". Assim, cabe a premissa de que a macropolítica não se translada de forma neutra, linear e ahistórica para os Estados-membro, e que existe uma certa autonomia das instituições universitárias na tomada de decisões.

Passemos a algumas aproximações entre o modelo de formação docente do EEES e da OCDE entre 1995 e 2010.

De início, cabe afirmar que o paradigma da Unesco - aprendizagem ao longo da vida - recebeu outro significado da União Europeia com um sentido econômico e mercantil, ao propor a formação centralizada no indivíduo (RUÉ, 2007). E, mais, aprofundou a visão de que cabe ao indivíduo (aprendente) ser ativo, protagonista, além de comprometer-se com as exigências das empresas, dominar formas de comunicação e de participação, aprender a aprender, possuir domínio de línguas e possuir responsabilidade pessoal e um espírito empreendedor (BRIÑAS, 2010).

Contudo, de uns tempos para cá, não faltam planejadores, experts e burocratas ${ }^{4}$ convencidos de que a educação pode ser tratada de maneira racional, produtiva. Para tanto, criam agências e organizações especializadas para calcular os resultados, cruzar os índices, ranquear os países e induzir 
ações e planos para gerar a competitividade entre eles. Em seguida, apontam aos governos os indivíduos e as instituições mais produtivas e competitivas, refazendo os seus lucros potenciais.

De fato, também é verdade que as TIC provocaram modificações nas profissões, inclusive nos currículos de formação. Em alguma medida, os indicadores ou notas obtidas pelos estudantes indicam os cérebros mais promissores e produtivos sob a lógica de um mercado competitivo. Nessas circunstâncias históricas, sob o sentido econômico e mercantil da aprendizagem ao longo da vida, concebido pelos governos e ministros da União Europeia, são reforçados os elementos de desvalorização da profissão docente, com esvaziamento do fazer pedagógico, político e social desses trabalhadores da educação.

Note que as agências de créditos passaram a decidir como selecionar, formar e manter os melhores professores no sistema de ensino. $O$ fato é que as agências de fomento e créditos, ${ }^{5}$ governos e empresários dos Estadosmembros estão assumindo os programas internacionais de comparação de indicadores educativos. Sabe-se que tais agências contam com a anuência dos governos locais. Sabe-se, ainda, que a partir de dados obtidos são estabelecidas as metas econômicas, e tais agências ranqueiam os países e realizam cruzamentos entre os sistemas de ensino e determinam um único padrão universal.

Para os experts das agências e dos organismos multilaterais de créditos, há uma distorção no sistema, pois os níveis de crescimento econômico e tecnológico continuam insuficientes e com pouca competitividade; os trabalhadores estão com baixa escolaridade e sem o domínio dos instrumentos e tecnologias virtuais; e, ao mesmo tempo, os governos dispensam orçamento generoso para pagamento de docentes cuja formação não atende ao mercado. Nessa situação, os empresários afirmam ser grave essa distorção! Por que o Estado continua financiando uma educação sem resultados positivos? Propuseram então, como objetivo, "conseguir una escuela menos custosa para los presupostos públicos e mais útil para la economia y maximizar los resultados y minimizar los costos" (TATO, 2005, p. 271).

Essa situação - de direcionamento de recursos financeiros do Estado para a educação, quando essa não apresenta os resultados desejados do ponto de vista da lógica da racionalização, eficácia e eficiência das políticas sociais - revela um descontrole e um obstáculo a ser corrigido. Afirmam os arautos financeiros que não se pode continuar a dispensar recursos para pagamento de professores, se os resultados desejados não são alcançados. Desse modo, a direção proposta induz aproximar universidade e escola das empresas e estreitar os níveis de formação com as novas vagas de trabalho. 
Nessa conjuntura, os planejadores, burocratas e empresários passam a ver na educação um espaço para o crescimento econômico e de lucros, se for dirigida por resultados e estratégias rígidas. Essa situação, atrelada aos cíclicos de crises do capital, acompanhada das tecnologias, fizeram os planejadores, técnicos, burocratas e governos enxergarem a educação como objeto com potencialidades para fazer alavancar um tipo de crescimento econômico. Portanto, as metas e necessidades do mercado passam a determinar a formação superior e, nela, a formação na graduação e pós-graduação no país.

\section{CONSIDERAÇõES FINAIS}

No ordenamento proposto pelos chefes de Estado e ministros de Educação, que modelo de formação docente está subjacente no EEES e OCDE? Os documentos indicam a manutenção de um modelo predatório de exploração, o que significa dizer que tais medidas buscam instituir meios de opressão e intensificação do trabalho docente. Desde a Declaração de Sorbonne (1998) e a Declaração de Bolonha (199), a educação superior passa por modificações, traduzidas na mobilidade de estudantes, docentes e investigadores, na aplicação do sistema europeu de créditos de transferência e no sistema de reconhecimento de diplomas e níveis de formação. Essas alterações modificam o ethos acadêmico da universidade, pois o espírito empresarial torna-se predominante, acompanhado de ações em que o estudante assume sua própria formação e os professores são facilitadores da aprendizagem. Nessa configuração política do EEES, a ordem social se subordina ao imperativo econômico com o eixo estruturante das relações capitalistas.

Em relação à formação docente, nos países da União Europeia, passou-se a exigir também o curso de master para ingresso na profissão docente; significa dizer que, depois do curso de graduação, o licenciado deverá fazer um mestrado para estar em condições de disputar vaga no magistério (GIL, 2011; MONTERO, 2006).

Espera-se do docente: saber conhecer e utilizar metodologias didáticas nos processos e ambientes virtuais; saber utilizar os modelos de avaliação e redirecionar objetivos; administrar e produzir situações concretas de aprendizagem, integrando as TIC aos desenhos dos processos de formação; ser capaz de trabalhar em equipe e em redes. De modo que, os processos de ensino e aprendizagem tenham um currículo baseado em competências, no fortalecimento das aptidões individuais e resultados mensuráveis.

Dentre as atribuições e tarefas dos professores, os governos insistem em uma formação consoante com as exigências dos distintos mercados de 
trabalho. Do professor, ainda, espera-se dominar e conduzir a gestão de forma racional; saber indicar onde o aluno pode buscar o conhecimento e informações; saber agir com grupos multiculturais e possuir domínio de linguagens interculturais (RUÉ, 2007; ZABALA, 2005). Ser um "facilitador de aprendizagens e que a mudança efetiva ocorre nos métodos de ensino, colocando o fracasso no individuo", diz Suárez ( 2010, p. 27).

No processo de ensino e aprendizagem, todas as atividades do aluno passam a ser quantificadas, mensuradas e avaliadas, exigindo-se constante ordenamento de objetivos, competências graduais e metodologias de resultados. Exige-se conhecer o processo de aprendizagem orientado para qualidade e inovação; empreender ações e situações de aprendizagem; saber avaliar experiências pedagógicas e empreender competências básicas para distintas situações (RAMIREZ, 2005; BRIÑAS,2010); evitar exposições magistrais; executar modos de aprendizagens cooperativas; e dominar diferentes estratégias e técnicas de trabalho individual e em grupo (BENITO y CRUZ, 2005; OLIVA, 2010).

Os postulados dos governos da União Europeia silenciam-se diante do agravamento das condições sociais da população empobrecida e revisitam os velhos preceitos liberais, entre eles: aptidão, competitividade, individualismo, produtividade e racionalidade. Depois de uma década de vigência, os fracassos dessa política econômica são visíveis nas altas taxas de desemprego e inúmeras manifestações da população nas ruas e praças. Da universidade, espera-se que adote modelos organizativos flexíveis, eficientes, dinâmicos, criativos, inovadores e uma cultura de competitividade para produzir resultados efetivos e quantificáveis. Desse ordenamento político, econômico e jurídico, desencadeia-se um modelo de política educacional subordinada ao modelo econômico, na tentativa de aproximar universidade e a escola das empresas. Essa premissa circula nos ambientes de decisões políticas e econômicas, coexistindo com uma visão capitaneada pelos chefes de Estado, ministros de Educação e empresários; e outra conduzida pelos movimentos sociais e populares que defendem a universidade e a escola como bens públicos, e a formação como um direito de todos e um dever do Estado. Assim, a constante reprodução do capital exige de nós uma contínua luta pela educação como um direito humano e social para todos e em todos os países.

TEACHER FORMATION AS SEEN BY EU EDUCATION MINISTERS AND HEADS OF STATE ABSTRACT: This article discusses the political order which gave rise to the European Space for Higher Education and teacher formation established therein in the light of the European Commission Communication, approved documents and resolutions 
published in the EU Official Gazette which led to a model of education and formation of professionals for the member states focused on ongoing learning, which proposes to convert the university and the school into service agencies. It analyzes the cycle of conferences of ministers and heads of state, the strategic planks, basic skills, abilities and aptitudes required of students in order to bring school and business closer together, and develop an entrepreneurial spirit in people at all levels. It also points out that during the process, teacher formation is associated with a type of conservative economic growth in which flexibility, employability, competitiveness, individualism, efficiency, digital culture and rationality are seen as assumptions underlying educational policy and practice.

KEYWORDS:Teacher formation. Education and Formation in the ESHE. Educational policy.

\section{LA FORMACIÓN DOCENTE EN LA VISIÓN DE LOS MINISTROS DE EDUCACIÓNY JEFES DE ESTADO DE LA UE}

RESUMEN: El presente artículo problematiza el ordenamiento político que originó el Espacio Europeu de Educación Superior y, en él, la formación docente instituída a la luz de los Comunicados de la Comisión Europea, documentos aprobados y resoluciones publicadas en el Diario Oficial de la Unión Europea que desencadenan un modelo de educación y formación de profesionales para los Estados miembros orientado para el aprendizado a lo largo de la vida, proponiendo la conversión de la universidad y la escuela en agencias de servicios. Analiza en el ciclo de conferencias de ministros y jefes de Estado los ejos estratégicos, las competencias básicas, las habilidades y aptitudes que se exigen de los alumnos, con el fin de aproximar la escuela de las empresas, además de desarrollar el espírito empresarial en los indivíduos en todos los niveles. Apunta, todavía que, durante el proceso se asocian la formación de profesores a un tipo de crecimiento económico conservador en el que flexibilidad, empleabilidad, competitividad, individualismo, eficiencia, cultura digital y racionalidad como supuestos conductores de las políticas y las prácticas de educación.

Palabras claves: Formación Docente. Educación y Formación en el EEES. Política Educacional.

\section{NOTAS}

1. Neste texto, para a identificação dos documentos - Comunicados da Comissão Europeia -, optou-se por manter a expressão $\mathrm{COM}+$ o número final conforme indicado nos documentos, proposituras e normativas aprovadas na União Europeia e subscritas pelos Estados-membros, em um total de 29 países em junho de 2011.

2. Os países que fazem parte da OCDE são: Alemanha, Austrália, Áustria, Bélgica, Canadá, Dinamarca, Eslováquia, Espanha, Estados Unidos, Finlândia, França, Grécia, 
Hungria, Israel, Islândia, Irlanda, Itália, Japão, Holanda, Luxemburgo, México, Nova

Zelândia, Noruega, Polônia, Portugal, Republica Checa, Reino Unido, Suécia, Suíça e Turquia (até 2011).

3. O Projeto DeSeCo (Definition and Selection of Competencies) iniciou-se em 1997, desenvolvido pela OCDE sob a direção da Suíça. O objetivo principal é construir um marco de referência conceitual, amplo e relevante, para o desenvolvimento das competências chaves na perspectiva da aprendizagem ao longo de toda a vida e que sirva para avaliar as competências no nível internacional (BRIÑAS, 2010, p. 27-34).

4. A Conferência Permanente de Ministros Europeus da Educação desempenha significativo papel na definição de políticas para a educação.

5. Agências de créditos são: Banco Mundial, Fundo Monetário Internacional e Banco Interamericano de Desenvolvimento, Banco Central Europeu e Organização Mundial de Comércio. Instituições são: Comitê Econômico e Social Europeu, Unesco , OCDE, Conferência Permanente de Ministros Europeus, Comissão Europeia, Conselho Europeu, Associação das Universidades Europeias e Agência Europeia de Educação (EURYDICE)

\section{REFERÊNCIAS}

ANTUNES, F. Globalização e europeização das políticas educativas: percursos processos e metamorfoses. In: Sociologia, problemas e práticas. n. 47, p. 125-143, 2005.

BENITO, A.; CRUZ, A. (Coord.). Nuevas claves para la docencia universitária. Espanha, Ediciones Narcea, 2005.

BRIÑAS, L. T. Las competencias básicas: el nuevo paradigma curricular en Europa. In: Foro de Educación: pensamiento, cultura y sociedad. Salamanca, n. 12, p. 25-44, 2010. COMISSÃO DAS COMUNIDADES EUROPEIA. Crecimiento, competitividad y empleo retos y pistas para entrar en el siglo XXI. Libro Blanco, 1993.

COMISSÃO DAS COMUNIDADES EUROPEIA. Ensinar e aprender: rumo à sociedade cognitiva. COM 59 final. Bruxelas, 1995.

COMISSÃO DAS COMUNIDADES EUROPEIA. Tornar o espaço europeu de aprendizagem ao longo da vida uma realidade. COM 678 final. Bruxelas, 2001.

COMISSÃO DAS COMUNIDADES EUROPEIA. Educação e formação: urgem as reformas para coroar com êxito a estratégia de Lisboa. COM 685 final. Bruxelas, 2003.

COMISSÃO DAS COMUNIDADES EUROPEIA. Investir eficazmente em educação e formação: um imperativo europeu. COM 779 final. Bruxelas, 2003.

COMISSÃO DAS COMUNIDADES EUROPEIA. Competências chaves para a aprendizagem permanente. COM 962 final. Bruxelas, 2006.

COMISSÃO DAS COMUNIDADES EUROPEIA. Melhorar a qualidade da formação do professorado. COM 392 final. Bruxelas, 2007. 
CONSELHO EUROPEU. Recomendacion 962 sobre las competencias claves para el aprendizaje permanente. 2006.

CONSELHO DA UNIÃO EUROPEIA Resolução do Conselho sobre a aprendizagem ao longo da vida de 27 de junho de 2002. Diário Oficial da União Europeia, p. C/163. 2002.

DIÁRIO OFICIAL DA UNIÃO EUROPEIA. Sobre a aprendizagem ao longo da vida. 27 de junho, p. C/ 163. 2002.

DIÁRIO OFICIAL DAS COMUNIDADES EUROPEIAS - DOCE, n. C142/1. 2002.

EURYDICE. La profesión docente en Europa: perfil, tendencias e intereses. Informe IV:EI atractivo de la profesión docente en el siglo XXI. Educación Secundaria Inferior General. Temas clave de la educación en Europa, v. 3. Bruxelas, 2004.

EURYDICE. Reformas de la profesión docente - análisis histórico: 1975-2002. Informe de la profesión docente en Europa: perfil, tendencias y problemática. Bruxelas, 2005.

EGUIZÁBAL, A. J.( Dir.). Repensar y construir el Espacio Europeu de Educación Superior: políticas, tendencias, escenarios y procesos de innovación. Madrid: Editorial Dykinson, 2008.

FONSECA, M. O Banco Mundial e a educação: reflexões sobre o caso brasileiro. In: GENTILI, P. Pedagogia da exclusão. Petrópolis: Editora Vozes, 1995. p. 159-183.

GENTILI, P. A falsificação do consenso. Petrópolis: Editora Vozes, 1998.

GIL, L.V. (Org.). Governanza y políticas de formación inicial de profesores en la Europa Mediterránea. Valência, Espanha: Editora Tirant lo Blanch, 2011. p.15-55.

MAUÉS, O. A política da OCDE para a educação e a formação docente. A nova regulação? In: Educação, v. 34, n. 1, p. 75-85, 2011.

MONTERO, M. L. Profesores y profesoras en un mundo cambiante: el papel clave de la formación inicial. In: Revista de Educación, p. 66-86, 2006.

OCDE. Attracting, developing, and retaining effective teachers: pointers for policy develoment. 2005. Disponível em: http://www.oecd.org/education/school/45139005.pdf. OCDE. Creating, effective teaching and learning environments: firts results form Talis (2009). Disponível em: www.oecd.org/edu/talis/firtst results.

OLIVA, A. J. Contemplando Bolonia: una decada de acontecimientos en la formación del Espacio Europeo de Educación Superior. In: Foro de Educación: pensamiento, cultura y sociedad, Salamanca, n.12, p. 69-91, 2010.

RAMIREZ, T. G. El espacio europeo de educación superior: una nova oportunidad para la universidad. In: BRAVO, P. C.; PONS, J. P. (Coord.) La universidad en la Unión Europea. Espanha, 2005, p. 27-53.

RUÉ, J. Ensenar en la univesidad: el EEES como reto para la educación superior. Espanha: Ediciones Narcea, 2007.

SUÁREZ, A. J. G. La plena integración de la universidad espanola en el EEES. Espanha, Las Plamas de Gran Canaria: Servicios de Publicaciones, 2010. 
TATO, M. S. Política educativa europea. In: Revista de Educación, n. 337, p. 251-278, 2005.

UNESCO. Aprender a ser: el mundo de la educación hoy e mañana. Relatório Edgar Faure. Madrid, 1972.

UNESCO. Relatório Jacques Delores. La educación encierra un tesoro. Madrid: SantiIhana, 1993.

UNESCO. Hacia las sociedades del conocimiento. Madrid: Ediciones Unesco, 2005.

UNESCO. Fundamentos de la planificación de la educación. IIPE. Madrid, 2007.

VINÃO, A. Sistemas educativos, culturas escolares e reformas. Espanha: Morata, 2002.

ZABALA, J. M. G. El espacio europeo de educación superior, un reto para las universidad. Espanha: Ediciones Octaedro/ICE-UB, 2005.

MARIA ABÁDIA SILVA: professora do Programa de Pós-Graduação da Faculdade de Educação da Universidade de Brasília.

E-mail: abadia@unb.br 